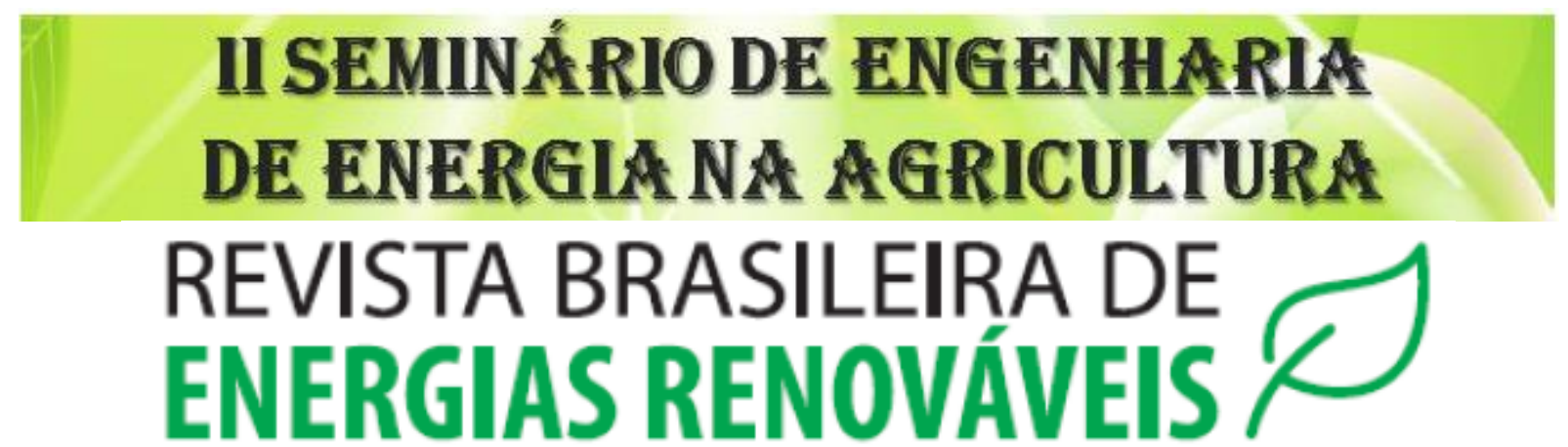

\title{
PROJETO CONCEITUAL DE UMA RESIDÊNCIA UNIFAMILIAR UTILIZANDO TÉCNICAS DE ENERGIAS RENOVÁVEIS ${ }^{1}$
}

Ricardo Paganin ${ }^{2}$, Jair Antônio Cruz Siqueira ${ }^{2}$, Samuel Nelson Melegari de Souza ${ }^{2}$, Janaína Bedin $^{2}$

${ }^{1}$ Apresentado no $2^{\circ}$ Seminário de Engenharia de Energia na Agricultura: 30/11/2017UNIOESTE, Campus Cascavel.

${ }^{2}$ Universidade Estadual do Oeste do Paraná - UNIOESTE, PPGEA - Programa de Pós Graduação em Energia na Agricultura - Nível Mestrado, Cascavel-PR. engpaganin@ gmail.com, jair.siqueira@unioeste.br, ssouza@unioeste.br, janainabedin@hotmail.com

\section{RESUMO}

A sociedade tem discutido muito sobre sustentabilidade nos últimos anos, os primeiros debates sobre o assunto tiveram início nas décadas de 60 e 70, essa tendência vem se disseminando cada vez mais nos dias atuais, em que não só a construção civil, mas toda sociedade de uma forma geral, está percebendo a necessidade de preocupar-se com os impactos ambientais causados ao planeta. Este trabalho teve como objetivo apresentar um projeto arquitetônico de uma residência unifamiliar utilizando técnicas alternativas com princípios sustentáveis e energias renováveis, apresentaram-se soluções tecnológicas e seus benefícios, visando o bom aproveitamento e economia de recursos naturais. Foram abordados diversos sistemas como captação de águas das chuvas para usos não potáveis, geração de eletricidade através de energia solar e da força dos ventos com um aerogerador de pequeno porte, além do aquecimento de água com radiação solar, que aplicados a uma residência unifamiliar tem o objetivo de melhorar seu desempenho energético. Esses sistemas foram estudados para melhor atender a residência, sem grandes modificações no projeto e construção da mesma. Com o desenvolvimento do trabalho pode-se verificar que o alinhamento das ideias de um projeto arquitetônico com a utilização de sistemas 
renováveis pode ser implementado, reduzindo o consumo da edificação. Palavras-chave: residência sustentável, sistemas sustentáveis, sustentabilidade na construção, energias renováveis.

\title{
CONCEPTUAL DESIGN OF A SINGLE-FAMILY RESIDENCY OF RENEWABLE ENERGY TECHNIQUES
}

\begin{abstract}
Society has discussed much about sustainability in recent years, the first debates on the subject began in the $60 \mathrm{~s}$ and $70 \mathrm{~s}$, this tendency is becoming more and more widespread in the present day, in which not only the construction, but every society in general, is realizing the need to be concerned about the environmental impacts caused to the planet. This work aimed to present an architectural design of a single family dwelling using alternative techniques with sustainable principles and renewable energies, presented technological solutions and their benefits, aiming at the good use and saving of natural resources. Several systems were approached such as rainwater harvesting for non-potable uses, electricity generation through solar energy and wind power with a small wind turbine, and water heating with solar radiation, which applied to a single family dwelling has the goal of improving their energy performance. These systems were studied to better meet the residence, without major modifications in the design and construction of the same. With the development of the work it can be verified that the alignment of the ideas of an architectural project with the use of renewable systems can be implemented, reducing the consumption of the building.
\end{abstract}

Keyword: sustainable living, sustainable systems, sustainability in construction, renewable energy.

\section{Introdução}

A habitação tem a necessidade de atender a demanda de crescimento populacional, porém, os projetistas para atender esse preceito devem reavaliar sua atuação, melhorando as relações do projeto e o meio ambiente, tendo em vista a sustentabilidade (LAMBERTS, 2004).

A quantidade de recursos disponíveis fez com que parte da população se acostumasse com o desperdício, mas os recursos não renováveis têm capacidade de exploração limitada. Desta 
forma percebe-se que é necessária a implantação de sistemas onde as edificações se tornem mais independentes, produzindo energia para seu próprio consumo e desperdiçando menos água para fins não potáveis (PEREIRA, 2003).

A engenharia visa a união de conhecimentos técnicos, científicos e matemáticos com objetivo de criar e aperfeiçoar soluções, gerando economia, eficiência e desenvolvimento para a sociedade. Se tratando de construções sustentáveis deve-se repensar na maneira de utilização dos recursos naturais e energéticos, criando uma nova consciência de uso, para atender as necessidades do homem moderno sem que se agrida o meio ambiente e os recursos naturais (MEDEIROS, 2012).

Segundo Conselho Brasileiro de Construção Sustentável - CBCS (2011) se assume que o conceito de preservação ambiental surgiu nos anos 60, após um grande crescimento industrial em vários países. Naquela época, os recursos naturais eram usados de maneira despreocupada com os efeitos prejudiciais ao longo do tempo. Surgindo o questionamento sobre dois fatos: não seria possível renovar os recursos diante a intensidade de sua exploração e a necessidade de adotar um novo método de analisar a natureza. Essas ideias demonstraram que é preciso revisar a integração entre as atividades humanas e seu relacionamento com o ecossistema e os recursos naturais.

A sustentabilidade de uma edificação inicia-se no conceito de projeto, em que o profissional deve buscar conciliar as características naturais do ambiente com forma da edificação, ou seja, deve-se prever o posicionamento da edificação de uma maneira útil e otimizada, de modo a aproveitar os recursos naturais (vento e insolação) evitando a utilização de máquinas que consomem energia para climatização artificial (MEDEIROS, 2012).

Existem inúmeras maneiras para aumentar a eficiência energética das edificações, entre elas está o aquecimento solar de água, que se torna uma alternativa eficiente em substituição às formas tradicionais, assim como a utilização de energia solar e eólica para produção de energia elétrica (LAMBERTS, 2010).

Os sistemas solares de aquecimento de água coletam energia da radiação solar e a transformam em calor, distribuído através de ar ou água quente até o destino onde será utilizado ou armazenado para uso posterior (ROAF, 2009).

Além do aquecimento da água a energia solar pode ser coletada e transformada diretamente em energia elétrica. O Brasil é um país privilegiado, com altos níveis de radiação 
solar, inclusive superior ao das nações desenvolvidas, porém todo esse potencial não reflete no uso expressivo desse sistema (TIBA, 2000).

Segundo Lamberts (2010) é chamado de sistema fotovoltaico (SFV) o conjunto de elementos necessários para ser feita a conversão direta da energia solar em energia elétrica, com atributos adequados para alimentar aparelhos elétricos e eletrônicos, como lâmpadas, televisores, geladeiras e outros. O SFV tem o painel fotovoltaico como principal componente e pode incluir, variando da aplicação, dispositivos para controle, supervisão, armazenamento e condicionamento de energia elétrica.

De acordo com Seguel (2009) o agrupamento de células fotovoltaicas (FV) é conhecido como módulo fotovoltaico. As células fotovoltaicas são produzidas com materiais duradouros, resistentes a intempéries, normalmente o silício. Carvalho (2013) salienta que existem vários modelos de células fotovoltaicas, porém os mais utilizados são os sistemas: monocristalino, policristalino e o amorfo.

Outra fonte de energia que pode ser aproveitada é a energia eólica, proveniente do movimento de massas de ar, ou seja, o vento. Essa energia tem vários aproveitamentos, como por exemplo a moagem de grãos (aplicação mais antiga), assim como a geração de energia elétrica. No caso de geração de energia elétrica necessita-se de um aerogerador, composto basicamente por uma torre de sustentação, um gerador elétrico e um conjunto de pás que captam a energia do vento e acionam o gerador (Magalhães, 2009).

Este trabalho teve como objetivo agrupar as funcionalidades de uma edificação sustentável com a utilização de meios renováveis de geração de energia, como a energia solar e a energia eólica, buscando aperfeiçoar a eficiência energética de uma edificação localizada na cidade de Nova Prata do Iguaçu, além da utilização de águas pluviais.

\section{Materiais e métodos}

O projeto foi realizado em uma área residencial, o loteamento tem grande importância para o desenvolvimento da cidade de Nova Prata do Iguaçu, localizada na Rua Primavera, lote $\mathrm{n}^{\circ}$ 01 da quadra $\mathrm{n}^{\circ}$ 06, Loteamento Anselmo Grahl - Bairro Alto, conforme a Figura 1, devendo seguir todas as normas previstas pelas leis municipais. O lote possui 432,00 $\mathrm{m}^{2}$ sendo $27,00 \mathrm{x}$ $16,00 \mathrm{~m}$, onde a residência terá a fachada principal voltada a norte na testada de 27,00 metros. 


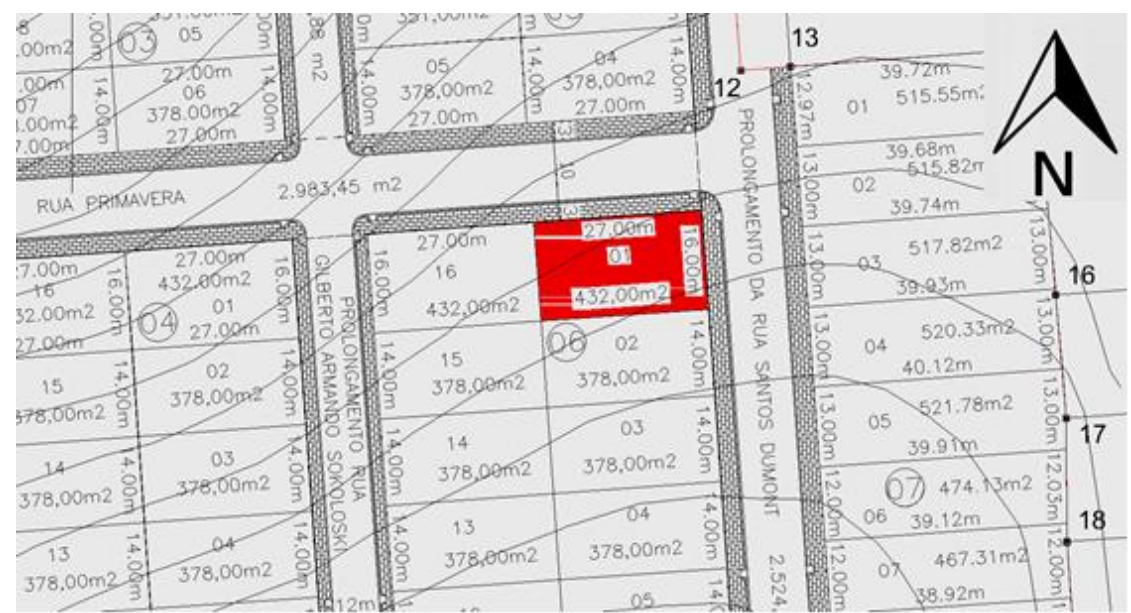

Figura 1. Loteamento Anselmo Grahl, lote em destaque (NOVA PRATA DO IGUAÇU, 2013)

De acordo com o Plano Diretor da cidade de Nova Prata do Iguaçu, o terreno encontrase em uma ZRM - Zona Residencial de Média Densidade, sendo assim seus índices urbanísticos são: área mínima de lote $360 \mathrm{~m}^{2}$; testada mínima $12 \mathrm{~m}$; taxa de ocupação de $80 \%$; coeficiente de aproveitamento máximo 1,0; taxa de permeabilidade do solo mínima 10\%; recuo frontal $3 \mathrm{~m} \mathrm{e}$ recuo lateral e fundos $1,5 \mathrm{~m}$.

A residência teve como objetivo atender a uma família de 5 pessoas, sendo assim, o programa de necessidades considerou: varanda; sala de estar; sala de jantar; cozinha; três dormitórios; banheiro social; lavanderia e uma vaga de garagem.

Adotou-se um consumo diário de água de $150 \mathrm{~L} \mathrm{dia}^{-1} \mathrm{hab}^{-1}$, que de acordo com Tomaz (2000) refere-se a edificações residenciais. O consumo diário foi calculado através da Equação 01 .

$$
C_{d}=P * q
$$

Onde:

$C_{d}=$ consumo diário $(1 /$ dia $)$;

$P=$ população (hab);

$q=$ consumo per capita (1/dia.hab).

De acordo com Tordo (2004) 33\% do consumo diário vai para descarga do vaso sanitário logo este valor foi utilizado como base para consumo de água não potável. Para o cálculo do reservatório superior utilizou-se o critério estabelecido pela NBR 5626 (ABNT, 1998) para o reservatório total não potável, que não pode ser inferior ao consumo diário e não deve ultrapassar 
em duas vezes o consumo diário. Para este trabalho foi adotado um acréscimo de $25 \%$ no volume, conforme Equação 02.

$$
C_{R}=C_{d} *(1+0,25)
$$

Onde:

$C_{R}=$ Consumo diário acrescido (1/dia);

$C_{d}=$ consumo diário (1/dia);

Para o cálculo da área de captação de água da chuva utilizou-se o método prático inglês de acordo com a NBR 15527 (ABNT, 2007) em que o volume de chuva é obtido pela Equação 03:

$$
V=0,05 * P * A
$$

Onde:

$V=$ é o valor numérico do volume de água aproveitável e o volume de água da cisterna (1);

$P=$ é o valor numérico da precipitação média anual $(\mathrm{mm})$;

$A=$ é o valor numérico da área de coleta em projeção $\left(\mathrm{m}^{2}\right)$.

Em relação ao aquecimento da água para banho utilizou-se os parâmetros na NBR 7198 (ABNT, 1998) e NBR 15569 (2008), em que considerou-se uma média de dois banhos diários por habitante com consumo de 50 litros por banho. Por esse critério o consumo diário considerado de água quente para o banho foi de 500 litros. Considerou-se que o sistema de aquecimento terá eficiência de aquecer 100 litros de água para cada $1 \mathrm{~m}^{2}$ de área.

Para obter a capacidade de geração de energia elétrica do sistema fotovoltaico analisouse a área disponível para instalação dos módulos fotovoltaicos e utilizou-se a Equação 04 de Rüther (2004). 


$$
E=\frac{A * E_{f f} * G_{p o a} * R}{100}
$$

Onde:

$E$ = energia gerada pelo sistema $(\mathrm{kWh} / \mathrm{dia})$;

$A=$ área total do sistema $\left(\mathrm{m}^{2}\right)$;

$E_{f f}=$ eficiência de conversão da tecnologia fotovoltaica utilizada (potência instalada/área do módulo);

$G_{\text {poa }}=$ média mensal do total da irradiação solar incidente no plano do arranjo fotovoltaico $\left(\mathrm{kWh} / \mathrm{m}^{2} / \mathrm{dia}\right)$;

$R=$ rendimento do sistema, inversor e conexões (adotado 0,8 ).

Em relação à instalação do aerogerador, de acordo com Camargo e Schubert (2007) o potencial pode ser calculado pela Equação 05:

$$
P=\frac{1}{2} * \rho * A_{r} * V^{3} * C_{p} * \eta
$$

Onde:

$P=$ potência $(\mathrm{W})$;

$\rho=$ densidade do $\operatorname{ar}\left(\mathrm{kg} / \mathrm{m}^{3}\right.$, entre 1 e $1,2-$ ao nível do mar 1,293);

$A_{r}=$ área de varredura do rotor $\left(\mathrm{m}^{2}\right)$;

$V=$ velocidade do vento $(\mathrm{m} / \mathrm{s})$;

$C_{p}=$ coeficiente aerodinâmico de potência do motor (máx. 0,45. Teórico 0,593);

$\eta=$ eficiência do conjunto gerador/transmissões mecânicas e elétricas (entre $0,93-0,98$ ).

A partir do levantamento de dados necessários pode-se então realizar o desenvolvimento do projeto conceitual de uma edificação com critérios de sustentabilidade utilizando o software Autocad para desenvolvimento do projeto 2D e o software Sketchup para o desenvolvimento do projeto

em

3D.

\section{Resultados e discussão}

Incialmente realizou-se os cálculos para servirem de subsídios no desenvolvimento do projeto. Levantou-se o consumo diário de água aplicando-se a Equação 01, sendo o valor obtido 
de $750 \mathrm{~L} \mathrm{dia}^{-1}$, deste valor 247,5 $\mathrm{L} \mathrm{dia}^{-1}$ (33\%) são estimados para descarga e cálculo do reservatório para coleta de água da chuva.

O volume do reservatório superior para água não potável foi calculado aplicando-se a Equação 02, sendo o valor necessário de 309,37 litros. A Companhia de Saneamento do Paraná SANEPAR recomenda que a reserva sirva para 2 (dois) dias, sendo assim o reservatório deverá ter capacidade de armazenar 618,74 litros, com base na disponibilidade comercial, optou-se por instalar um reservatório superior de água não potável com capacidade de 750 litros.

Em relação a capacidade de captação de água de chuva, aplicou-se a Equação 03, para uma precipitação média anual de 1800 mm, sendo assim a capitação será de 7740 litros. Optou-se por instalar uma cisterna de 5000 litros para atender ao armazenamento da água da chuva, que quando cheia poderá atender a demanda de 20 dias. Em tempos de estiagem a rede de descarga poderá ser ligada a rede de distribuição de água da concessionária, tendo funcionamento normal. Neste caso pode-se considerar uma economia de $33 \%$ da água potável distribuída pela concessionária, visto que nas épocas de disponibilidade de chuva esta água poderá ser substituída pela água da chuva. Desenvolveu-se um esquema do sistema conforme Figura 2.

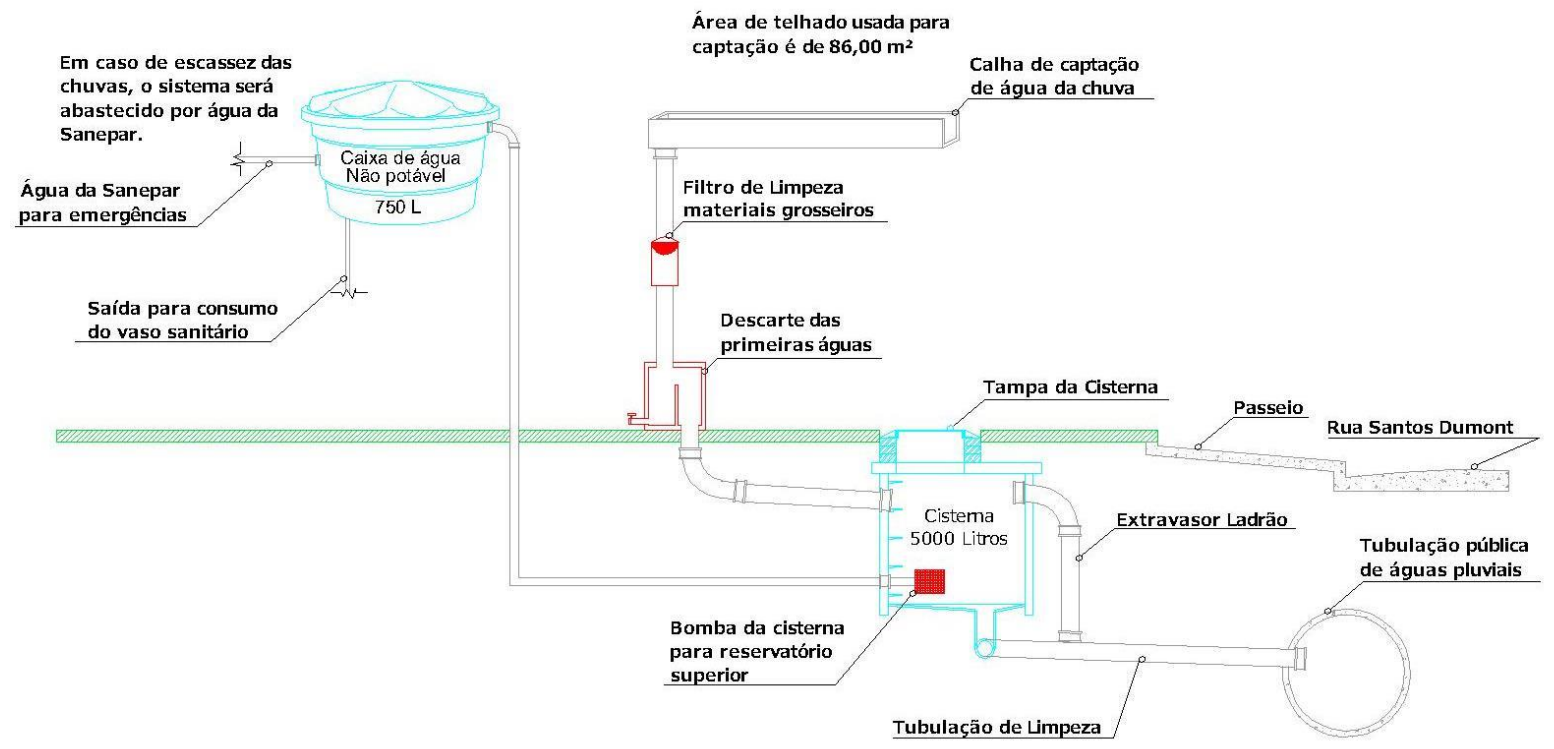

Figura 2. Esquema de utilização da água da chuva.

Em relação ao sistema de geração de energia iniciou-se pela determinação da geração com a utilização do painel fotovoltaico, aplicando-se a Equação 04, tendo como resultado uma geração de 3,59 $\mathrm{kWh} \mathrm{dia}^{-1}$. O mesmo foi feito para o dimensionamento do sistema de geração de energia eólica aplicando-se a Equação 05 com diâmetro do rotor adotado igual 1,17 m, obtendo- 
se um potencial gerador de 19,29 $\mathrm{kWh}$ mês $^{-1}$. O valor mensal total de geração com a utilização das fontes renováveis (solar e eólica) atingido foi de 126,99 $\mathrm{kWh}$ mês $^{-1}$.

De acordo com a Empresa de Pesquisa Energética - EPE, em 2013 o consumo per capito de energia elétrica na região sul do Brasil foi de 231,91 $\mathrm{kWh}$ mês $^{-1}$, com isso a demanda seria maior que a geração de energia, porém ainda sim haveria uma economia no consumo de energia elétrica disponibilizado pela concessionaria responsável de 54,75\%. O esquema de geração de energia pelos sistemas solar e eólico é representado na Figura 3.

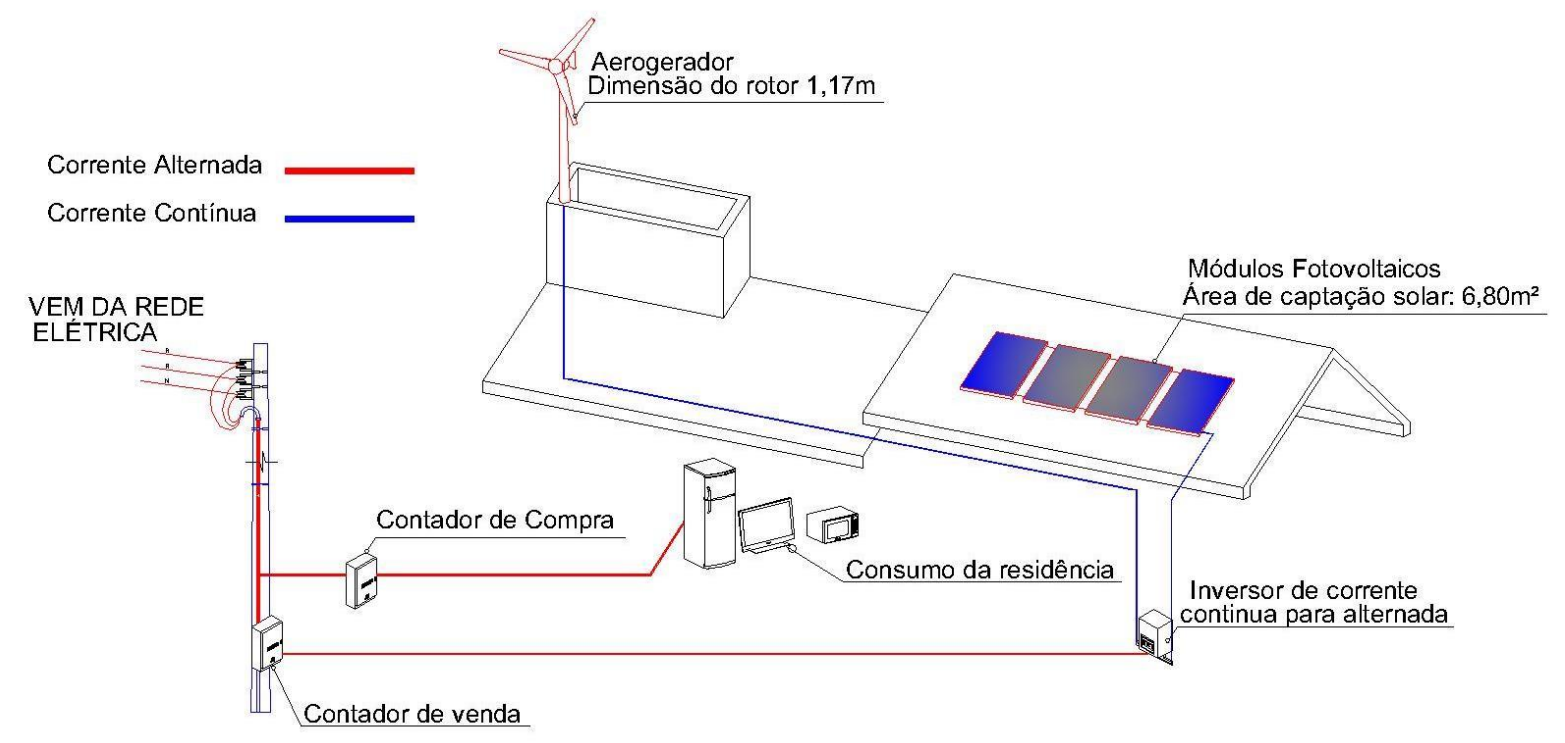

Figura 3. Esquema de sistemas geradores de energia elétrica.

Dimensionou-se ainda o sistema de aquecimento de água com a utilização da radiação solar, nesse caso considerando a eficiência de aquecimento de 100 litros para $1 \mathrm{~m}^{2}$ de área de instalação do equipamento e uma demanda de 500 litros por dia, a edificação necessitaria de uma área de instalação do sistema de aquecimento de $5 \mathrm{~m}^{2}$. O sistema dimensionado foi esquematizado conforme Figura 4. 


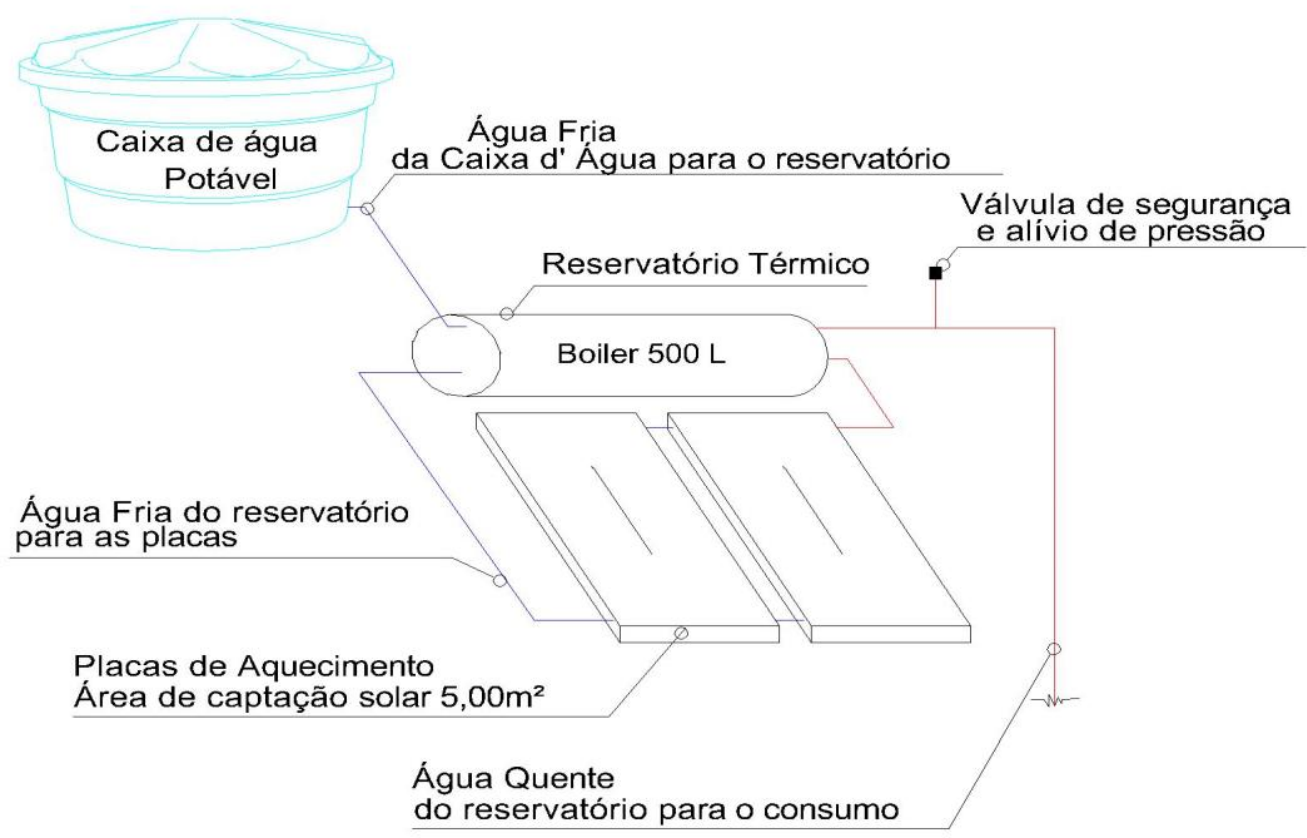

Figura 4. Esquema do sistema de aquecimento da água com sistema solar.

Com esse sistema o consumo de energia elétrica de acordo com dados da Eletrobras/Procel (2007) pode ser reduzido em até $25 \%$.

Com a determinação das dimensões dos sistemas de geração de energia de aquecimento da água, pode-se representar o projeto em formato 3D, para verificar a representação arquitetônica da edificação com os sistemas instalados, conforme Figura 5. 


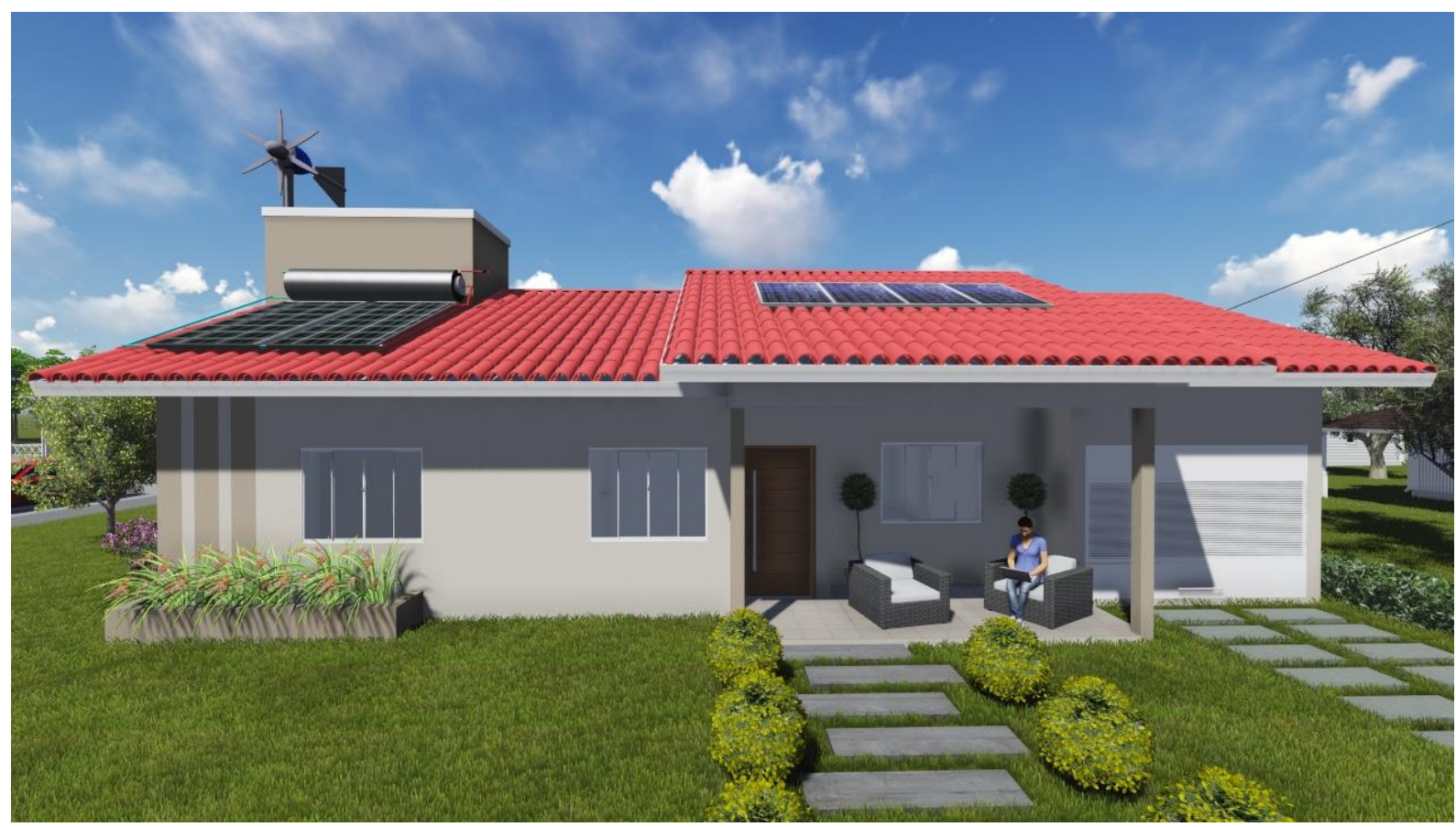

Figura 5. Vista frontal da representação arquitetônica da edificação.

De acordo com Neufert (1976) a fachada projetada voltada para o norte tem melhor eficiência para captação da energia solar, ao passo que os dormitórios ficaram voltados para o leste, evitando o sol da tarde, tornando o ambiente mais agradável.

\section{Conclusões}

O desenvolvimento do trabalho mostrou que a sustentabilidade e a eficiência energética em edificações podem ser abordadas sob diversos aspectos, estando associada a redução do consumo de água, energia e melhorias nas edificações, contribuindo para a satisfação e conforto dos usuários.

Os sistemas para produção de energia elétrica (placas fotovoltaicas e aerogerador) tem um bom desempenho, considerando que para atender uma residência de consumo não elevado, podendo assim fazer grande diferença nos gastos financeiros beneficiando os usuários.

$\mathrm{O}$ aquecimento de água pelo calor do sol tornou-se uma boa alternativa auxiliando na economia de energia, porém deve sempre ser associado ao uso de chuveiro elétrico, pois em épocas de pouca incidência solar o sistema pode não atender a demanda da edificação.

A captação de água das chuvas tem uma nobre importância economizando água potável, 
que para o conceito de sustentabilidade é fundamental, além gerar economia na tarifa de água e auxiliar minimizando enchentes.

Considerando o exposto, mostra-se perfeitamente possível instalar sistemas de energias renováveis com objetivo de minimizar os impactos ambientais, pois tem grande vantagem de explorá-los localmente, assim não comprometendo a disponibilidade de recursos para as gerações seguintes, visando incentivar a utilização de técnicas ecológicas nas construções buscando uma sociedade mais sustentável.

\section{Referências}

ASSOCIAÇÃO BRASILEIRA DE NORMAS TÉCNICAS. NBR 5626: instalação predial de água fria. Rio de Janeiro, 1998.

. NBR 7198: projeto e execução de instalações de instalações prediais de água quente

- procedimento. Rio de Janeiro, 2008.

NBR 15527: água de chuva - aproveitamento de coberturas em áreas urbanas para fins não potáveis - requisitos. Rio de Janeiro, 2008.

NBR 15569: sistema de aquecimento solar de água em circuito direto - projeto e instalação - procedimento. Rio de Janeiro, 2008.

CAMARGO, Schubert. Manual de Avaliação Técnico-Econômica de Empreendimentos Eólio-Elétricos. 1 ed. Curitiba: COPEL/LACTEC, 2007, 101p.

CARVALHO, C. R. F. de. Sistema Fotovoltaico Isolado: Uma Aplicação Prática No Projeto Xapuri. Monografia (Especialização em Formas Alternativas de Energia), Universidade Federal de Lavras, Lavras. 2013.

CBCS. Condutas de Sustentabilidade no Setor Imobiliário Residencial. Disponível em: <http://www.cbcs.org.br> Acesso 01 de setembro de 2013.

ELETROBRAS - Centrais Elétricas Brasileiras S.A; PROCEL - Programa Nacional de Conservação de Energia Elétrica. Pesquisa de Posse de Equipamentos e Hábitos de Uso - Ano Base 2005 - Classe Residencial - Relatório Brasil. Rio de Janeiro: ELETROBRAS/PROCEL, 2007.

LAMBERTS, R.; DUTRA, L.; PEREIRA, F. O. R. Eficiência energética na arquitetura. 2. ed. São Paulo: Pro Livros, 2004.

LAMBERTS, R.; et al. Casa eficiente : consumo e geração de energia. Florianópolis: UFSC/LabEEE, 2010. 
MAGALHAES, M. V. Estudo de utilização da energia eólica como fonte geradora de energia no Brasil. Monografia (Graduação em Ciências Econômicas), Universidade Federaal de Santa Catarina, Florianópolis, 2009.

MEDEIROS, V. A. Casa Sustentável. Minas Gerais, 2012. Ministério do Meio Ambiente. Disponível em: Acesso em 09 nov. 2017.

PEREIRA, Márcio C. Habitação e Meio Ambiente: uma abordagem crítica para o projeto sustentável. 2003. Dissertação (Mestrado em Arquitetura), Universidade Federal do Rio Grande do Sul - Pontifícia Universidade Católica do Paraná, Curitiba, 2003.

ROAF, Sue; FUENTES, Manuel; THOMAS, Sthefanie. Ecohouse: A casa ecologicamente sustentável. $3^{\mathrm{a}}$ ed. Porto Alegre: Bookman, 2009. 488 p.

RÜTHER, R. Edifícios Solares Fotovoltaicos: o potencial da geração fotovoltaica integrada a edificações urbanas e interligada à rede elétrica pública no Brasil. $1^{\circ} \mathrm{ed}$. Florianópolis: LABSOLAR, 2004. 114 p.

SEGUEL, J. I. L. Projeto de um sistema fotovoltaico autônomo de suprimento de energia usando técnica MPPT e controle digital. Dissertação (Mestrado em Engenharia Elétrica), Universidade Federal de Minas Gerais, Belo Horizonte. 2009.

TIBA, C. (Coord.). Atlas Solarimétrico do Brasil: banco de dados terrestres. Recife: Ed. Universitária da UFPE, 2000. 111p.

TOMAZ, Plínio. Previsão de consumo de água. Interface das instalações prediais de água e esgoto com os serviços públicos. São Paulo: Comercial Editora Hermano \& Bugelli Ltda, 2000.

TORDO, O. C. Caracterização e avaliação do uso de águas de chuva para fins potáveis. Dissertação (Mestrado em Engenharia Ambiental), Universidade Regional de Blumenau, Blumenau, 2004. 